\title{
Anabases
}

ANABASES Traditions et réceptions de l'Antiquité

$20 \mid 2014$

Varia

\section{Kostas VLASSOPOULOS, Greeks and Barbarians}

\section{Yohann Le Tallec}

\section{OpenEdition \\ Journals}

Édition électronique

URL : http://journals.openedition.org/anabases/5182

DOI : 10.4000/anabases.5182

ISSN : 2256-942

\section{Éditeur}

E.R.A.S.M.E.

\section{Édition imprimée}

Date de publication : 1 novembre 2014

Pagination : 443-445

ISSN : 1774-4296

\section{Référence électronique}

Yohann Le Tallec, « Kostas vlassopoulos, Greeks and Barbarians », Anabases [En ligne], 20 | 2014, mis en ligne le 01 novembre 2014, consulté le 22 septembre 2020. URL : http://journals.openedition.org/ anabases/5182 ; DOI : https://doi.org/10.4000/anabases.5182

Ce document a été généré automatiquement le 22 septembre 2020.

(c) Anabases 


\title{
Kostas VLASSOPOULOS, Greeks and Barbarians
}

\author{
Yohann Le Tallec
}

\section{RÉFÉRENCE}

Kostas VlassoPoulos, Greeks and Barbarians, Cambridge, Cambridge University Press, 2013, 392 p.

24,99 livres / ISBN 978-0-521-76468-1

1 Le livre de Kostas Vlassopoulos est une synthèse, très ambitieuse sur le plan conceptuel, des interactions sociales, politiques et culturelles entre Grecs et non-Grecs de la période archaïque à la période hellénistique. Certes, la question n'est pas neuve mais les récents succès cinématographiques des films d'Oliver Stone Alexander et de 300 de Franck Miller ont fortement contribué à réactualiser cette question.

2 Accordant une place très conséquente de son introduction à l'historiographie de la question, l'auteur rappelle la prégnance des analyses privilégiant l'angle du conflit, l'opposition Grecs/Barbares renvoyant à une distinction plus large entre Occident et Orient. Les communautés grecques apparaissent dès lors comme le lieu privilégié de l'éclosion d'une civilisation occidentale caractérisée par la démocratie et la liberté de pensée. Les Barbares sont quant à eux associés à une aire civilisationnelle différente dominée par le despotisme et la théocratie. Les deux guerres médiques deviennent logiquement le paradigme de cet affrontement séculaire. C'est la conception défendue dès 1846 par John Stuart Mill et par ceux qui ont vu dans l'évènement du 11 septembre 2011 un prolongement de cet antagonisme. Certes, l'auteur rappelle utilement que la critique de l'impérialisme occidental a depuis conduit à reconsidérer ce point de vue. À cet égard, la publication en 1978 du livre consacré à l'orientalisme par Edward Saïd a joué un rôle central en déconstruisant le discours occidental sur l'Orient, un discours né avec Les Perses d'Eschyle. L'ethnocentrisme des Grecs a également été étudié par François Hartog, ce dernier montrant comment le discours d'Hérodote manifeste en 
définitive peu d'intérêt pour la compréhension des cultures autres, ce discours créant ainsi des stéréotypes essentiels à la construction d'une identité grecque. Prolongeant cette approche, Edith Hall a récemment étudié la façon dont la tragédie grecque a inventé la notion de Barbares.

3 Kostas Vlassopoulos remet également en perspective l'histoire d'une approche concurrente, celle privilégiant le concept d'hellénisation portée par Johann Gustav Droysen en 1836 dans la première édition de sa monumentale Geschichte des Hellenismus. Droysen crée à cette occasion le concept d'hellénisme pour décrire la fusion des cultures consécutives à la conquête de l'empire perse par Alexandre le Grand. À la différence de l'approche centrée sur les conflits et la polarité, l'hellénisation privilégie les interactions et les échanges en insistant sur leur caractère progressif. Cependant, et l'auteur insiste tout particulièrement sur ce point, le concept d'hellénisation donne une image trop souvent univoque : l'adoption par des non-Grecs d'éléments constitutifs de la culture grecque n'en font pas pour autant des Grecs.

4 Ce livre pose ensuite la question, essentielle et trop souvent éludée, de la méthode d'analyse. Jusque-là, les relations Grecs/Barbares ont généralement été étudiées sous l'angle chronologique avec une différenciation forte opérée entre les modalités de ces relations à l'époque archaïque (c. $700-479$ av. J-C), pendant la période classique (479-323 av. J-C) et, enfin, pendant la période hellénistique (323-31 av. J-C). Les deux guerres médiques (490-479 av. J-C) et les conquêtes d'Alexandre (334-323 av. J-C) viennent utilement fournir les points d'inflexion entre ces périodes. Selon ce schéma traditionnel, la période archaïque est caractérisée par la transformation du monde grec au sortir du monde fragmenté de l'âge du fer (1100-700 av. J-C). Autour de 700, le monde grec émerge comme une périphérie stimulée par le contact avec le monde proche-oriental. Suivant la voie tracée par l'adoption de l'alphabet phénicien par les Grecs, les traditions artistiques du Proche-Orient conduisent à la période orientalisante. Les artistes et artisans grecs adoptent alors des techniques et des motifs iconographiques venus du Proche-Orient ce qui permit au monde grec de sortir des traditions établies par l'art géométrique. Commence alors un lent processus de transformations qui caractérise l'histoire de l'art grec. Cette transformation de la culture et de la société grecques via le stimulus proche-oriental s'accompagne du processus graduel de formation d'une identité grecque à partir d'identités locales et régionales qui caractérisent l'âge du fer. Comme le rappelle l'auteur, un des défauts majeurs de cette approche chronologique est d'éluder le fait que les évolutions attribuées aux guerres médiques ou aux conquêtes d'Alexandre les ont en fait largement précédées (par exemple l'influence grecque sur les communautés vivant au sein de l'empire perse existe bien avant la conquête d'Alexandre comme le montre le monument funéraire en l'honneur de Mausole à Halicarnasse). L'autre grand défaut de cette approche est de considérer que chaque période historique est dominée par un seul type d'interaction.

5 Le premier cadre d'analyse des interactions Grecs-Barbares défini par l'auteur privilégie l'espace des réseaux, celui où s'opère migrations et déplacements (ceux opérés par les commerçants, marins, artisans, mercenaires ou artistes); celui aussi où s'échangent les biens économiques (les esclaves recouvrant également en partie le précédent sous-ensemble), les idées et les technologies.

6 L'auteur envisage ensuite l'aire géographique des colonies. Ce monde des apoikiai est celui de communautés humaines auto-organisées, souvent indépendantes 
politiquement de leur cité d'origine. Un grand nombre d'interactions Grecs-Barbares s'inscrivent logiquement dans le contexte particulier que les archéologues et historiens ont récemment défini comme des sociétés de frontière. Deux formes d'interactions avec les communautés non-grecques sont privilégiées : celles aboutissant d'une part à la création d'une identité grecque et, d'autre part, à une forme que l'auteur qualifie de canonique de la culture grecque.

7 Le troisième cadre d'analyse envisagé pour l'étude des relations Grecs-Barbares est l'espace dessiné par le panhellénisme. Ce cadre est défini par l'imaginaire d'une littérature et d'une mythologie communes. Les grands sanctuaires panhelléniques, au premier rang desquels Delphes et Olympie, constituent la territorialité du panhellénisme et un point de contact privilégié entre Grecs et non-Grecs.

Le dernier cadre d'analyse envisagé est celui des grands empires proche-orientaux qui se constituent au cours du second millénaire. Leur émergence et l'affirmation de leur puissance ont des conséquences de premier plan pour les communautés hellénophones d'Asie mineure et des bords de la mer Noire (confrontations militaires, négociations, interventions politiques jouèrent en effet un rôle essentiel dans l'histoire de ces communautés). Par leur besoin conséquent en soldats, administrateurs, artisans ou conseillers, les relations qui se nouent ici entre Grecs et non-Grecs sont multiples.

9 L'intensité et l'extrême diversité de ces interactions dessinent les contours d'une première forme de globalisation au sein de l'espace méditerranée. Kostas Vlassopoulos insiste tout particulièrement sur l'émergence et l'affirmation de référents culturels communs et d'une culture matérielle partagée mais également sur l'extrême diversité dans les façons dont ces communautés appréhendèrent et modifièrent les éléments constitutifs de cette koinè globale. Ce livre, très novateur et original dans son approche, s'intéresse aux modalités (ici le pluriel est essentiel) par lesquelles la culture grecque fut façonnée grâce aux interactions avec les communautés non-grecques. Jusqu'à un certain degré, ces quatre espaces recouvrent des aires géographiques différentes: l'espace des empires couvre la Méditerranée orientale ; l'espace des colonies privilégie la Méditerranée occidentale et la mer Noire. Plus important, ces différents cadres recouvrent des types d'interactions différents à la fois sur le plan social, culturel, économique et politique. La grande vertu de l'analyse proposée dans cet ouvrage est qu'elle permet de ne pas segmenter les types d'interaction mais aussi d'envisager les relations Grecs/Barbares sur la longue durée. Mais ce processus de globalisation permet dans le même temps aux systèmes locaux de se redéfinir (concept de glocalisation). Cette variété de modalités par lesquelles les communautés locales adoptèrent et adaptèrent les éléments globaux de la koinè grecque constituent un des éléments les plus intéressants et les plus stimulants de cet ouvrage très remarquable. 


\section{AUTEURS}

YOHANN LE TALLEC

ANHIMA (UMR 8820)

yletallec@netcourrier.com 